\title{
Relationship between the IgA antibody response against Streptococcus mutans GbpB and severity of dental caries in childhood
}

\author{
Natália Helena Colombo ${ }^{a}$, Jesse Augusto Pereira ${ }^{a}$, Márjully Eduardo Rodrigues da Silva ${ }^{a}$, \\ Laís Fernanda Fonseca Ribas ${ }^{a}$, Thaís Manzano Parisotto ${ }^{b}$, \\ Renata de Oliveira Mattos-Graner ${ }^{\mathrm{c}}$, Daniel J. Smith ${ }^{\mathrm{d}}$, Cristiane Duque ${ }^{\mathrm{a}, *}$ \\ ${ }^{a}$ UNESP - Univ Estadual Paulista, Araçatuba Dental School, Department of Pediatric Dentistry and Public Health, Araçatuba, SP, Brazil \\ ${ }^{\mathrm{b}}$ Sao Francisco University, Dental School, Laboratory of Microbiology and Molecular Biology, Bragança Paulista, SP, Brazil \\ ${ }^{\mathrm{c}}$ UNICAMP - University of Campinas, Piracicaba Dental School, Department of Oral Diagnosis, Piracicaba, SP, Brazil \\ ${ }^{\mathrm{d}}$ Forsyth Institute, Department of Immunology and Infectious Disease, Cambridge, MA, USA
}

\section{A R T I C L E I N F O}

\section{Article history:}

Received 8 January 2016

Accepted 15 March 2016

\section{Keywords:}

Early childhood caries

Imunoglobulin A

S. mutans

Glucan binding proteins

\begin{abstract}
A B S T R A C T
Objective: Explore the associations between the severity of dental caries in childhood, mutans streptococci (MS) levels and IgA antibody response against Streptococcus mutans GbpB. Moreover, other caries-related etiological factors were also investigated.

Design: 36-60 month-old children were grouped into Caries-Free (CF, $n=19$ ), Early Childhood Caries (ECC, $\mathrm{n}=17$ ) and Severe Early Childhood Caries (S-ECC, $\mathrm{n}=21$ ). Data from socio-economic-cultural status, oral hygiene habits and dietary patterns were obtained from a questionnaire and a food-frequency diary filled out by parents. Saliva was collected from children for microbiological analysis and detection of salivary IgA antibody reactive with $S$. mutans GbpB in western blot.

Results: S-ECC children had reduced family income compared to those with ECC and CF. There was difference between CF and caries groups (ECC and S-ECC) in MS counts. Positive correlations between salivary IgA antibody response against $\mathrm{GbpB}$ and MS counts were found when the entire population was evaluated. When children with high MS counts were compared, S-ECC group showed significantly lower IgA antibody levels to GbpB compared to CF group. This finding was not observed for the ECC group. Conclusions: This study suggests that children with S-ECC have reduced salivary IgA immune responses to S. mutans GbpB, potentially compromising their ability to modify MS infection and its cariogenic potential. Furthermore, a reduced family income and high levels of MS were also associated with S-ECC.
\end{abstract}

(C) 2016 Elsevier Ltd. All rights reserved.

\section{Introduction}

Dental caries is an infectious disease that results from the dissolution of tooth mineral by acids derived from bacterial fermentation of sucrose and other dietary carbohydrates (Loesche, 1996). When occurring in young children, this disease is called early childhood caries (ECC). According to the American Academy of Pediatric Dentistry (2014) ECC is characterized by the presence of one or more decayed (noncavitated or cavitated lesions), missing (due to caries), or filled tooth surfaces in any primary tooth of children under the age of six. However, in children younger than

\footnotetext{
* Correspondence at: UNESP - Univ Estadual Paulista, Araçatuba Dental School, Department of Pediatric Dentistry and Public Health, R. José Bonifácio, 1193, CEP: 16015-050, Araçatuba, SP, Brazil.

E-mail addresses: cristianeduque@yahoo.com.br, cduque@foa.unesp.br (C. Duque).
}

three years of age, any sign of smooth-surface caries is indicative of severe early childhood caries (S-ECC). From ages three through five, one or more cavitated, missing (due to caries) or filled smooth surfaces in primary maxillary anterior teeth or a decayed, missing or filled score of greater than or equal to four (age 3), five (age 4) or six (age 5) surfaces also constitutes severe S-ECC. The disease can progress and lead to destruction of the primary dentition affecting negatively children's physical and mental health, as well as increasing the risk of new caries lesions in the permanent dentition (Ng \& Chase, 2013; Isaksson, Alm, Koch, Birkhed, \& Wendt, 2013).

The mutans streptococci (MS) group, mainly Streptococcus mutans, is most strongly associated with the pathogenic process of ECC because of its high presence in the biofilms and saliva of the affected children (Ge, Caufield, Fisch, \& Li, 2008; Parisotto, SteinerOliveira, Silva, Rodrigues, \& Nobre-dos-Santos, 2010b). Three important cell-associated antigens (Ags) are correlated directly with the ability of S. mutans to adhere and accumulate in the tooth 
surfaces forming dental biofilm: antigen I/II (AgI/II); glucosyltransferases (GtfB, GtfC, GtfD) and glucan-binding proteins (GbpA, GbpB, GbpC, GbpD) (Smith, 2002). Ag I/II promotes interaction of bacterial proteins and host-derived components; Gtf catalyzes glucan synthesis and Gbps increase the binding of S. mutans to each other and to glucans deposited on tooth surfaces, contributing to the sucrose-dependent adherence to teeth (Smith, 2002). Several studies have demonstrated that induction of specific antibodies against these antigens, mainly $\mathrm{GtfB} / \mathrm{C}$ and $\mathrm{GbpB}$, can prevent the development of dental caries in animal models (Jespersgaard et al., 1999; Koga, Oho, Shimazaki, \& Nakano, 2002; Smith \& Taubman, 1996) and modify infection in humans (Smith \& Taubman, 1987).

Salivary immunoglobulins, particularly secretory IgA have major importance in the resistance of the mucosa to oral infections. The secretory IgA immune response represents the first line of adaptive immune defense against mutans streptococci, blocking microbial adhesins and potentially reducing oral colonization with this cariogenic microflora. Salivary IgA has also been shown to enhance the activity of several enzymes such as lactoferrins and lysozymes (Law, Seow, \& Townsend, 2007). A clinical study showed that the IgA antibody response against $S$. mutans GbpB was predominant in the first year of life and frequently correlated with the delay in the oral infection with $S$. mutans (Nogueira, Alves, Napimoga, Smith, \& Mattos-Graner, 2005). The intensity of IgA patterns against antigens of S. mutans was previously studied and lower levels of salivary IgA against GbpB were associated with higher caries risk (Parisotto et al., 2011). However, the relationship between IgA antibody levels against this antigen and different levels of caries has not yet been evaluated. The objective of this study was to explore the associations among the severity of dental caries in childhood, mutans streptococci levels and IgA response against $S$. mutans GbpB. Moreover, caries-related etiological factors were also investigated. The null hypotheses formulated was that immune response, MS levels, socio-economic-cultural aspects, hygiene and dietary habits presented by ECC and S-ECC are not different from that exhibited by CF children.

\section{Methods}

\subsection{Subjects}

The study population comprised 36- to 60-month-old children who attended the four public nursery schools in the city of Araçatuba, São Paulo, Brazil. The city's population has access to public water supply with fluoride level of $0.7 \mathrm{ppm}$. Children's parents as well as administrators at the preschools involved granted written permission for the study which was previously approved by the Research Ethics Committee of Araçatuba Dental School-Univ. Estadual Paulista (UNESP), Brazil (CAAE \# 13079213.4.0000.5420).

Data from socio-economic-cultural status, including family income and mother's education level and from dietary habits were obtained from a questionnaire and a food-frequency diary filled out by parents. The diet reflected food consumption of three consecutive days during the workweek, because in the weekend the diet can be highly variable. In addition to the diet data reported by parents, the preschool staff provided information about infant feeding in the school period, as many of the children were in school full time. This diet chart included the time of day that the children ate and drank anything and the content of all meals and snacks. The daily frequencies of total sugar exposure and consumption from baby bottles was calculated from chart data (Parisotto et al., 2010a).

Clinical examinations were performed at the school by a single calibrated examiner (NHC) previously training (Kappa value of
0.75) using mouth mirrors and probes under natural light. Decayed, missing and filled surfaces in deciduous teeth (dmfs) were counted in each child. The exclusion criteria for this study were: children suffering from systemic disease or using long-term medications or antibiotics less than one month before the examination and children with mucosal lesions. Children with only restored or missing teeth were also excluded. Preschoolers who had white chalky spot lesions were excluded from caries free group. All children were encouraged and instructed on dental hygiene and received all other necessary oral care. The inclusion criteria of this study comprise oral/systemic health children from both genders, 36-60 months of age. Initially sixty children were selected. Three of them were absent from schools when saliva was collected. So, fifty-seven children were divided into three groups according to oral health status: caries-free group (CF) $(n=19)$, early childhood caries group (ECC) $(n=17)$ and severe early childhood caries group (S-ECC) $(n=21)$. ECC was defined for this study as the presence of 1 through 3 decayed tooth surface (cavitated lesions) in primary teeth, S-ECC was defined as the presence of decayed surfaces score of $\geq 4$ (age 3 years), $\geq 5$ (age 4 years), with at least one smooth-surface carious lesion (American Academy of Pediatric Dentistry, 2014).

\subsection{Saliva samples}

About $2 \mathrm{ml}$ of unstimulated saliva was collected from children at afternoon and at least $1 \mathrm{~h}$ after feeding. Tubes were transported on ice to the laboratory and processed within $1 \mathrm{~h}$. After agitation, one hundred microliters of saliva were separated for microbiological procedures. The remaining saliva was clarified by centrifugation at $10000 \mathrm{rpm}$ at $4{ }^{\circ} \mathrm{C}$ for $10 \mathrm{~min}$. The supernatants were collected and $250 \mathrm{mM}$ EDTA was added to minimize salivary IgA aggregation. Aliquots of $50 \mu \mathrm{l}$ of each saliva samples were frozen at $-70^{\circ} \mathrm{C}$ until immunological analysis (Nogueira et al., 2005).

\subsection{Microbiological procedures}

Aliquots of saliva were homogenized by vortexing for $1 \mathrm{~min}$ and the suspensions were serially diluted in $0.9 \% \mathrm{NaCl}$ solution. Each dilution was cultivated in triplicate on Mitis Salivaris Agar (Difco Laboratories, Detroit, MI, USA) with $0.2 \mathrm{U} / \mathrm{mL}$ bacitracin for isolation of mutans streptococci (MS). All plates were incubated at $37^{\circ} \mathrm{C}$ for $48 \mathrm{~h}$ in a $5 \% \mathrm{CO}_{2}$ atmosphere. After $48 \mathrm{~h}$, the total number of colony-forming units (CFU) was counted using a stereoscopic microscope. Results were expressed as CFU/ml.

\subsection{Total salivary IgA level measurement}

The concentration of total IgA in saliva samples were determined by an enzyme-linked immunosorbent assay (ELISA) kit using a commercially available analysis kit (Mabtech Inc., Cincinnati OH, USA) and following the manufacturer's instructions.

\subsection{Western blot analysis of salivary antibody to mutans $G b p B$}

In order to analyze the influence of patterns of specificity of IgA response to S. mutans GbpB, levels of MS infection and caries status, Western blot assays were performed using saliva samples from children and tested against Ags extracted from a standard S. mutans strain (ATCC 25175). For Ags preparation, colonies of S. mutans from fresh Brain Heart Infusion Agar (BHI, Difco) were inoculated in $5 \mathrm{ml} \mathrm{BHI}$ broth and incubated for $18 \mathrm{~h}$. Bacterial cells were then harvested from $1 \mathrm{ml}$ of cultures previously adjusted to an absorbance of 1.0 (A550 nm). Cells were ressuspended in TE containing $100-\mu \mathrm{m}$-diameter zirconia/silica beads and mechanically disrupted using a Mini-BeadBeater (BioSpec) at maximum 
speed (2800 rpm) for 1-min pulses, three times, with a 30 -s rest on ice between pulses. Cell pellets were then boiled in Laemmli buffer for $5 \mathrm{~min}$, and protein extracts were separated by centrifugation at $4{ }^{\circ} \mathrm{C}$ (10000 rpm for $\left.4 \mathrm{~min}\right)$. Protein concentrations were determined by the method of Bradford and a total of $16 \mu \mathrm{g}$ of protein extract was used for Western blot analysis (Nogueira et al., 2005). Ags extracts were loaded per lane, separated by sodium dodecyl sulfate-6\% polyacrylamide gel electrophoresis, and transferred to nitrocellulose membranes. After transference, membranes were washed and blocked overnight at $4{ }^{\circ} \mathrm{C}$ (in Tris-buffered salineTween, $\mathrm{pH} 7.5,5 \%$ nonfat milk). Incubations with saliva samples diluted 1:100 were performed at room temperature for $2 \mathrm{~h}$. As negative controls, membranes were incubated only with blocking buffer, and as positive controls, membranes were incubated with a standard saliva sample obtained from an adult subject whose pattern of reaction with $S$. mutans antigen extracts had been previously measured. The secondary antibody was HRP-Goat AntiHuman IgA (1:4000 dilution) (Invitrogen, Life Technologies, USA). Immunoreactive bands were detected by autoradiography using ECL chemiluminescent substrate reagent kit (Invitrogen, Life Technologies, USA) according to the manufacturer's instructions. $\mathrm{X}$-ray films were scanned in a transluminator using a White Light Converter Plate (UVP, LLC, Upland, CA, USA) and the patterns of antigen recognition, including the number and intensity of reactive bands were analyzed with UVP Image software. The molecular weight of $S$. mutans $\mathrm{GbpB}$ was about $60 \mathrm{kDa}$. Migration position of $\mathrm{GbpB}$ were determined in parallel western blot assays performed with specific polyclonal rat antiserum to GbpB (Smith \& Taubman, 1996).

\subsection{Statistical analysis}

The statistical analysis was performed considering caries status: CF, ECC and S-ECC as the dependent variables. The comparisons among the groups were performed according to data distribution, considering Kolmogorov-Smirnov $\mathrm{Z}$ tests. ANOVA and Tukey tests were applied for age and sugar intake. Kruskal-Wallis and Mann-Whitney tests were applied for gender comparison, family income, mother's education level, artificial (bottle) feeding, mutans streptococci/lactobacilli counts and total IgA levels. Medians and ranges of bacterial counts were expressed as $\log (\mathrm{CFU}+1)$ and the constant 1 was added to CFU counts, when the sample showed zero CFUs. Pearson correlation tests were conducted to compare IgA levels against S. mutans GbpB and bacterial counts for the entire population. The reactivities of salivary IgA antibody with $S$. mutans GbpB were compared with respect to caries severity (CF, ECC and S-ECC) and mutans streptococci levels (low mutans streptococci - LMS and high mutans streptococci-HMS) using Mann-Whitney tests.

\section{Results}

Means/standard deviations obtained for caries levels (dmfs) were: CF (0), ECC $(2 \pm 1.06)$ and S-ECC (23.43 \pm 17.17$)$. Considering white spots lesions, dmfs were: CF (0), ECC $(2.94 \pm 1.67)$ and S-ECC $(28.28 \pm 18.76)$. There were no statistical differences among the groups in relation to age, gender, mother's education level, diet habits (artificial feeding and sugar intake) and total IgA levels (Table 1). Families of S-ECC children had reduced income compared to families of ECC and CF children showing a relationship between high scores of caries and economic condition of family. Statistical differences between $\mathrm{CF} \times \mathrm{ECC}$ and $\mathrm{CF} \times \mathrm{S}$-ECC children were observed for mutans streptococci (MS) counts. S-ECC children were heavily colonized by MS. There was a gradual

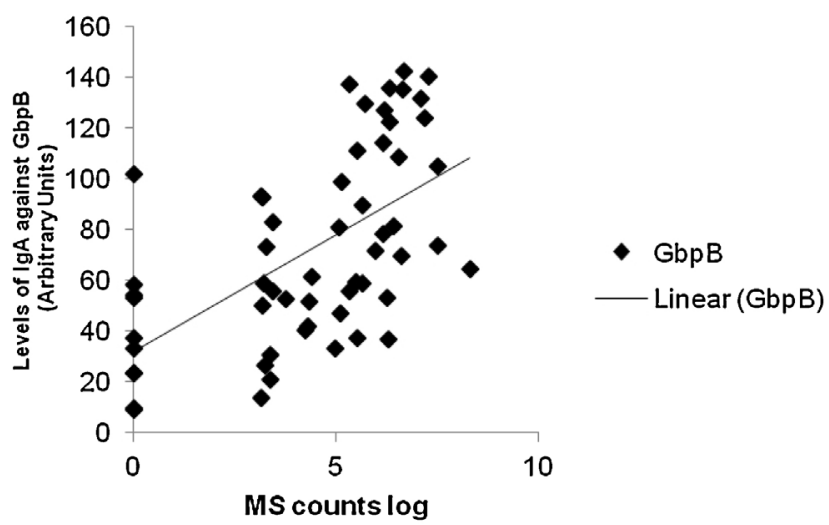

Fig. 1. Scatter plot showing correlation between levels of IgA antibody reactive with GbpB and mutans streptococci (MS). The analysis was carried out for the total population, regardless the caries status. Positive Pearson correlation $(R=0.583$, $\mathrm{p}=0.00)$ was observed for MS counts.

Table 1

Comparative analysis between the severity of early childhood caries and related etiological factors.

\begin{tabular}{|c|c|c|c|c|c|}
\hline & & $\mathrm{CF}$ & ECC & S-ECC & $p$ value \\
\hline Dmfs (mean $\pm \mathrm{SD}$ ) & & $0^{\mathrm{a}}$ & $2 \pm 1.06^{\mathrm{b}}$ & $23.43 \pm 17.17^{\mathrm{c}}$ & $\mathbf{0 . 0 0}$ \\
\hline Age (months) Mean \pm SD & & $46.26 \pm 5.05^{\mathrm{a}}$ & $45.94 \pm 9.83^{\mathrm{a}}$ & $48.10 \pm 8.59^{\mathrm{a}}$ & 0.664 \\
\hline \multirow[t]{2}{*}{ Gender (\%) } & Female & $47.37^{\mathrm{A}}$ & $35.29^{\mathrm{A}}$ & $52.38^{\mathrm{A}}$ & 0.571 \\
\hline & Male & 52.63 & 64.71 & 47.62 & \\
\hline Family income per month & $\leq \mathrm{R} \$ 1448.00^{*}$ & $41.1^{\mathrm{A}}$ & $25^{\mathrm{B}}$ & $64.71^{\mathrm{C}}$ & 0.05 \\
\hline Mother's education (\%) & Up to 8 years & $37.50^{\mathrm{A}}$ & $35.71^{\mathrm{A}}$ & $47.62^{\mathrm{A}}$ & 0.737 \\
\hline Mother's help with tooth brushing (\%) & & $82.35^{\mathrm{A}}$ & $80.0^{\mathrm{A}}$ & $65.0^{\mathrm{A}}$ & 0.961 \\
\hline Bottle feeding (\%) & & $82.36^{\mathrm{A}}$ & $66.67^{\mathrm{A}}$ & $85^{\mathrm{A}}$ & 0.692 \\
\hline Sugar intake & liquid & $4.21 \pm 1.37^{\mathrm{a}}$ & $4.02 \pm 1.18^{\mathrm{a}}$ & $4.56 \pm 1.38^{a}$ & 0.465 \\
\hline \multirow[t]{2}{*}{$($ mean $\pm S D)$} & solid & $2.70 \pm 0.90^{\mathrm{a}}$ & $3.17 \pm 1.43^{\mathrm{a}}$ & $2.97 \pm 1.40^{\mathrm{a}}$ & 0.565 \\
\hline & total & $6.88 \pm 1.62^{\mathrm{a}}$ & $7.19 \pm 1.66^{\mathrm{a}}$ & $7.53 \pm 2.32^{\mathrm{a}}$ & 0.579 \\
\hline $\begin{array}{l}\text { mutans streptococci } \\
\text { median (range) }\end{array}$ & $(\log \mathrm{UFC}+1)$ & $3.35(0-7.29)^{\mathrm{A}}$ & $3.74(0-6.66)^{\mathrm{A}}$ & $5.63(3.15-8.3)^{\mathrm{B}}$ & 0.012 \\
\hline $\begin{array}{l}\text { total lactobacilli } \\
\text { median(range) }\end{array}$ & $(\log U F C+1)$ & $0(0-6.79)^{\mathrm{A}}$ & $3.30(0-6.47)^{\mathrm{A}}$ & $1.97(0-6.72)^{A}$ & 0.447 \\
\hline Total IgA (ng/ml) Median (range) & & $99.15(24.52-114.24)^{\mathrm{A}}$ & $83.24(32.27-114.56)^{\mathrm{A}}$ & $88.04(18.17-109.31)^{\mathrm{A}}$ & 0.125 \\
\hline
\end{tabular}

a,b,c Different lower case letters show statistical difference among the groups, according to ANOVA and Tukey tests.

A,B,C Different upper case letters show statistical difference among the groups, according to Kruskal-Wallis and Mann-Whitney tests. CF-caries free, ECC-early childhood caries, S-ECC-severe early childhood caries.

R\$-Brazilian real. 1 US\$ $\sim$ R 3.50 (2015, August).

Bold represents values of $p<0.05$. 
Table 2

Medians (range) of total salivary IgA, distributed according to mutans streptococci levels.

\begin{tabular}{llll}
\hline & \multicolumn{2}{l}{ MS levels $^{\mathrm{a}, \mathrm{b}}$} & \\
\cline { 2 - 4 } & LMS & HMS & $p$ value \\
\hline CF & $101.9(24.52-114.24)$ & $91.05(60.04-107.43)$ & 0.375 \\
ECC & $81.93(32.27-107.43)$ & $84.55(48.02-114.56)$ & 0.341 \\
S-ECC & $98.92(18.17-104.14)$ & $84.10(26.01-109.31)$ & 0.357 \\
$p$ value & 0.380 & 0.243 & \\
\hline
\end{tabular}

a There was no statistical difference among groups of children (columns), considering each MS levels separately (LMS or HMS), using Kruskal-Wallis tests.

$\mathrm{b}$ There was no statistical difference inside each group of children (rows), comparing MS levels (LMS x HMS), using Mann-Whitney tests.

increase in the MS count with respect to the severity of the disease (Table 1). Considering the total population, positive correlations between salivary IgA levels to GbpB and MS counts were found (Fig. 1). For these reasons, children were paired according to levels of MS within each group. Considering the mean of MS counts of the population, the groups of children (CF, ECC and S-ECC) were subdivided as follows: LMS - low mutans streptococci count (with MS counts $\leq \log 4 \mathrm{CFU} / \mathrm{ml}$ ) and HMS - high mutans streptococci count (with MS counts $\geq \log 5 \mathrm{CFU} / \mathrm{ml}$ ). Comparing LMS and HMS, there was no significant difference among the groups in relation to total IgA levels (Table 2). The levels of IgA antibody reactive with GbpB were lower in S-ECC compared to ECC and CF children, only for HMS (Fig. 2). IgA antibody levels to $\mathrm{GbpB}$ increased for all groups, when compared with the same groups of children (CF, ECC and S-ECC) with LMS and HMS counts (Fig. 2). However, S-ECC children with high mutans streptococci counts showed significantly lower IgA antibody levels to $\mathrm{GbpB}$ compared to the CF group with HMS. No statistically significant differences were observed comparing ECC with the other groups with HMS (Fig. 2).

\section{Discussion}

Early childhood caries has a complex etiology with biological, behavioral, and socioeconomic influences (Arora, Schwarz, \& Blinkhorn, 2011; Ng \& Chase, 2013). For this reason, in this study, some factors determining oral health were concomitantly analyzed. S-ECC children had a reduced family income compared to CF and ECC groups, however, no difference among the groups were found in relation to mother's education level. High prevalence of dental caries in children with adverse socio-economic conditions was previously confirmed by another studies (Oliveira, Sheiham, \& Bönecker, 2008; Parisotto et al., 2010a). However, discrepancy in relation to level of mother's education was found in the literature, with children whose mothers had less than 8 years of education with high caries levels (Oliveira et al., 2008) and absence of difference between caries-free and caries group (Parisotto et al., 2010a), in agreement with our study. This lack of difference probably occurred because children were selected from the schools with similar social characteristics. A strong association between high frequency of sugar exposure and occurrence of dental caries has been established yet (Kalsbeek \& Verrips, 1994; Milgrom et al., 2000; Parisotto et al., 2010a). However, the present study did not find a significant difference in sugar exposure among the groups, similar to found in another study (Ohlund et al., 2007) which it was not correlated caries status with sugar intake frequency. One possible explanation for this finding is that the responses from questionnaires may have reflected present, not historical experience, which would have better revealed habits during the period when caries had started.

Several previous studies found mutans streptococcus is a significant factor for the presence of ECC (Ge et al., 2008; Milgrom

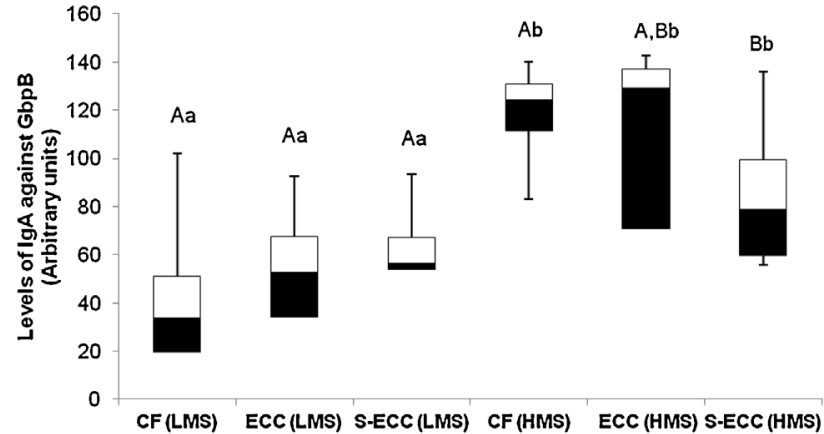

Fig. 2. Box plots of the western blot reactivity of salivary IgA antibody with $S$. mutans GbpB among the groups of children, distributed according to caries status (CF, ECC and S-ECC) and mutans streptococci levels (LMS and HMS). Bars indicate minimum and maximum values. Black and white boxes indicate lower and upper quartiles, respectively. Line in the middle of boxes is median.

A-Different upper case letters show statistical difference among groups of children considering each MS level separately (LMS or HMS), according to Mann-Whitney tests. For example: GbpB CF (LMS) x GbpB ECC (LMS).

a-Different lower case letters show statistical difference inside each group of children, comparing MS level (LMS x HMS), according to Mann-Whitney tests. For example: GbpB CF (LMS) x GbpB CF (HMS).

CF-caries free, ECC-early childhood caries, S-ECC-severe early childhood caries. LMS- Low mutans streptococcus levels.

HMS - High mutans streptococcus levels.

et al., 2000; Ohlund et al., 2007). Our results showed that S-ECC children were highly colonized by mutans streptococci compared with CF and ECC children. This information confirmed data from literature which have demonstrated that children with high $S$. mutans counts have more risk to develop dental caries (Ge et al., 2008; Milgrom et al., 2000; Ohlund et al., 2007). A recent systematic review and meta-analysis showed that there is scientific evidence of $S$. mutans transmission from mother to child especially when the mother is the primary caregiver (da Silva Bastos et al., 2015), although $18 \%$ of bacterial strains were from an unknown source (Kozai et al., 1999). The American Academy of Pediatric Dentistry (2014) recommended the reduction of mutans streptococci levels of mothers, primary caregivers and sibling(s), educating them on avoiding saliva-sharing behaviors (e.g., sharing spoons, cups and other utensils, cleaning a dropped pacifier or toy with their mouth), to reduce the child's risk of ECC.

The literature has shown that a better immune response to oral microorganisms, mainly $S$. mutans, may be a protective factor against the development of dental caries (Davidopoulou, Diza, Menexes, \& Kalfas, 2012; Nogueira et al., 2005; Tao et al., 2005). This observation may be valid for both innate and adaptive immune responses. Reduced levels of some antimicrobial peptides, components of innate immune response, are associated with caries in childhood (Davidopoulou et al., 2012; Tao et al., 2005). The action of salivary IgA against specific surface proteins of cariogenic bacteria such as $S$. mutans has been the subject of many studies (Nogueira et al., 2007, 2005; Parisotto et al., 2011), with focus on GbpB and Gtf expression. These proteins may be targets in the development of vaccines against dental caries (Kim et al., 2011; Smith \& Taubman, 1996). The immunization with GbpB induced an immune response that interfered with the accumulation of $S$. mutans and reduced the levels of dental caries in rats (Smith \& Taubman, 1996). The caries protection resulting from immunization of rats with Gtf was lower than observed after immunization with S. mutans GbpB. The same study showed that saliva of shamimmunized/S. mutans infected rats contained antibody to $\mathrm{GbpB}$ in saliva at the end of the experiment, indicating that infection with $S$. mutans can induce an immune response to this antigen. 
Preschoolers with a lower baseline level of salivary IgA antibody reactive with GbpB had 7.5 higher risk to develop caries, but any differences between CF and caries group (ECC mixed with S-ECC) in relation to salivary IgA against $S$. mutans antigens ( $\mathrm{GbpB}, \mathrm{Gtf})$ was found (Parisotto et al., 2011). The results of the current study are partially in accordance with this mentioned study. We did not find a difference in IgA antibody levels against $\mathrm{GbpB}$ between $\mathrm{CF}$ and ECC children, regardless of their mutans streptococci levels. However, difference was found in anti-GbpB antibodies levels between CF and S-ECC children, considering only children with high mutans streptococci levels (HMS), suggesting that reduced levels of IgA against GbpB may be related to high severity of dental caries. The absence of difference in total salivary IgA levels among the groups reinforces that heavily-infected S-ECC children have a reduced immune response against $\mathrm{GbpB}$, and this immunological failure could have contributed to the severity of caries status. Sudy demonstrated that salivary IgA levels to $S$. mutans antigens were higher in a caries-free group than in caries group and persisted in children from 3 to 11 years old (Bolton \& Hlava, 1982) demonstrated that $A$ recent study comparing specific IgA levels in three-year old children revealed increased concentrations of anti-S.mutans IgA and anti-S. sanguinis IgA in children who were culture positive for $S$. mutans compared with those who were culture negative (Malcolm et al., 2014).

Children infected with $S$. mutans showed a delay in the immune response to the $S$. mutans $\mathrm{GbpB}$ antigen during the first year of life (Nogueira et al., 2007). This study paired children according to mutans streptococci infection and they were divided in two groups: infected or non-infected children. In the current study, children were paired according to the mutans streptococci (MS) counts $(\mathrm{CFU} / \mathrm{ml})$ because a positive correlation was observed for this variable and IgA response to $S$. mutans $\mathrm{GbpB}$, for the total population, besides no children had zero $S$. mutans counts and can be considered non-infected. Then it was obviously expected that with the increasing of bacterial infection, higher host immune response to pathogen will occur (Nogueira et al., 2007).

The importance of GbpB for $S$. mutans viability has been studied by several investigators (Duque et al., 2011; Fujita, MatsumotoNakano, Inagaki, \& Ooshima, 2007; Matsumoto-Nakano, Fujita, \& Ooshima, 2007). Using a GbpB-deficient mutant strain, authors suggested that $\mathrm{GbpB}$ may have an important role in cell-wall construction, as well as in the cell separation and cell-wall maintenance in $S$. mutans, similar to murein hydrolases (Fujita et al., 2007). Furthermore, a GbpB-deficient mutant was more sensitive to acid $\mathrm{pH}$ in the acid killing assays (Matsumoto-Nakano et al., 2007), had decreased autolysis, increased cell hydrophobicity, and increased sensitivity to antibiotics and osmotic and oxidative stresses (Duque et al., 2011). These functions, associated with binding of $S$. mutans to glucans deposited on tooth surfaces, highlight the important role of GbpB in the biofilm formation and survival of $S$. mutans in the oral cavity (Matsumoto-Nakano et al., 2007). Thus a good strategy to control dental caries could be the interference in the virulence factors of $S$. mutans, such as GbpB, by means the development of vaccines to reduce its cariogenicity (Smith \& Mattos-Graner, 2008).

In conclusion, this study suggests that children with severe early childhood caries and high levels of mutans streptococci have reduced salivary IgA response to $S$. mutans $\mathrm{GbpB}$ showing that this parameter may influence the severity of dental caries in childhood. Furthermore, a reduced family income and high levels of MS were also associated with S-ECC.

\section{Conflict of interest}

The authors declare that they have no conflict of interest.

\section{Acknowledgements}

This study was supported by grants (2012/19235-5; 2013/ 12167-7) from São Paulo Research Foundation (FAPESP), São Paulo, SP, Brazil and Coordination for the Improvement of Higher Education Personnel (CAPES).

\section{References}

American Academy of Pediatric Dentistry (2014). Policy on early childhood caries (ECC): classifications, consequences, and preventive strategies. Oral Health Policies50-52.

Arora, A., Schwarz, E., \& Blinkhorn, A. S. (2011). Risk factors for early childhood caries in disadvantaged populations. Journal of Investigative and Clinical Dentistry, 2, $223-228$.

Bolton, R. W., \& Hlava, G. L. (1982). Evaluation of salivary IgA antibodies to cariogenic microorganisms in children: correlation with dental caries activity. Journal of Dental Research, 61, 1225-1228.

Davidopoulou, S., Diza, E., Menexes, G., \& Kalfas, S. (2012). Salivary concentration of the antimicrobial peptide LL-37 in children. Archives of Oral Biology, 57, 865-869.

Duque, C., Stipp, R. N., Wang, B., Smith, D. J., Höfling, J. F., Kuramitsu, H. K., et al. (2011). Downregulation of GbpB a component of the VicRK regulon, affects biofilm formation and cell surface characteristics of Streptococcus mutans. Infection and Immunity, 79, 786-796.

Fujita, K., Matsumoto-Nakano, M., Inagaki, S., \& Ooshima, T. (2007). Biological functions of glucan-binding protein B of Streptococcus mutans. Oral Microbiology and Immunology, 22, 289-292.

Ge, Y., Caufield, P. W., Fisch, G. S., \& Li, Y. (2008). Streptococcus mutans and Streptococcus sanguinis colonization correlated with caries experience in children. Caries Research, 42, 444-448.

Isaksson, H., Alm, A., Koch, G., Birkhed, D., \& Wendt, L. K. (2013). Caries prevalence in Swedish 20-year-olds in relation to their previous caries experience. Caries Research, 47, 234-242.

Jespersgaard, C., Hajishengallis, G., Huang, Y., Russell, M. W., Smith, D. J., \& Michalek, S. M. (1999). Protective immunity against Streptococcus mutans infection in mice after intranasal immunization with the glucan-binding region of S. mutans glucosyltransferase. Infection and Immunity, 67, 6543-6549.

Kalsbeek, H., \& Verrips, G. H. (1994). Consumption of sweet snacks and caries experience of primary school children. Caries Research, 28, 477-483.

Kim, M. A., Yang, Y. M., So, Y. R., Ko, Y. H., Lim, S. M., Lee, K. Y., et al. (2011). Development of a monoclonal antibody against glucosyltransferase D of Streptococcus mutans GS 5. Hybridoma (Larchmt), 30, 375-380.

Koga, T., Oho, T., Shimazaki, Y., \& Nakano, Y. (2002). Immunization against dental caries. Vaccine, 20, 2027-2044.

Kozai, K., Nakayama, R., Tedjosasongko, U., Kuwahara, S., Suzuki, J., Okada, M., et al. (1999). Intrafamilial distribution of mutans streptococci in Japanese families and possibility of father-to-child transmission. Microbiology and Immunology, 43, 99-106.

Law, V., Seow, W. K., \& Townsend, G. (2007). Factors influencing oral colonization of mutans streptococci in young children. Australian Dental Journal, 52, 93-100 [quiz 159].

Loesche, W. J. (1996). Microbiology of dental decay and periodontal disease, In S. Baron (Ed.), Medical microbiology4th ed. Galveston, TX: University of Texas Medical Branch at Galveston.

Malcolm, J., Sherriff, A., Lappin, D. F., Ramage, G., Conway, D. I., Macpherson, L. M., et al. (2014). Salivary antimicrobial proteins associate with age-related changes in streptococcal composition in dental plaque. Molecular Oral Microbiology.

Matsumoto-Nakano, M., Fujita, K., \& Ooshima, T. (2007). Comparison of glucanbinding proteins in cariogenicity of Streptococcus mutans. Oral Microbiology and Immunology, 22, 30-35.

Milgrom, P., Riedy, C. A., Weinstein, P., Tanner, A. C., Manibusan, L., \& Bruss, J. (2000). Dental caries and its relationship to bacterial infection hypoplasia, diet, and oral hygiene in 6- to 36-month-old children. Community Dentistry and Oral Epidemiology, 28, 295-306.

Ng, M. W., \& Chase, I. (2013). Early childhood caries: risk-based disease prevention and management. Dental Clinics of North America, 57, 1-16.

Nogueira, R. D., Alves, A. C., King, W. F., Gonçalves, R. B., Höfling, J. F., Smith, D. J., et al (2007). Age-specific salivary immunoglobulin a response to Streptococcus mutans GbpB. Clinical and Vaccine Immunology, 14, 804-807.

Nogueira, R. D., Alves, A. C., Napimoga, M. H., Smith, D. J., \& Mattos-Graner, R. O. (2005). Characterization of salivary immunoglobulin a responses in children heavily exposed to the oral bacterium Streptococcus mutans: influence of specific antigen recognition in infection. Infection and Immunity, 73, 5675-5684.

Ohlund, I., Holgerson, P. L., Backman, B., Lind, T., Hernell, O., \& Johansson, I. (2007) Diet intake and caries prevalence in four-year-old children living in a lowprevalence country. Caries Research, 41, 26-33.

Oliveira, L. B., Sheiham, A., \& Bönecker, M. (2008). Exploring the association of dental caries with social factors and nutritional status in Brazilian preschool children. European Journal of Oral Sciences, 116, 37-43. 
Parisotto, T. M., King, W. F., Duque, C., Mattos-Graner, R. O., Steiner-Oliveira, C. Nobre-Dos-Santos, M., et al. (2011). Immunological and microbiologic change during caries development in young children. Caries Research, 45, 377-385.

Parisotto, T. M., Steiner-Oliveira, C., Duque, C., Peres, R. C., Rodrigues, L. K., \& Nobredos-Santos, M. (2010a). Relationship among microbiological composition and presence of dental plaque sugar exposure, social factors and different stages of early childhood caries. Archives of Oral Biology, 55, 365-373.

Parisotto, T. M., Steiner-Oliveira, C., Silva, C. M., Rodrigues, L. K., \& Nobre-dos-Santos, M. (2010b). Early childhood caries and mutans streptococci: a systematic review. Oral Health \& Preventive Dentistry, 8, 59-70.

Smith, D. J. (2002). Dental caries vaccines: prospects and concerns. Critical Reviews in Oral Biology \& Medicine, 13, 335-349.

Smith, D. J., \& Mattos-Graner, R. O. (2008). Secretory immunity following mutans Streptococcal infection or immunization. Current Topics in Microbiology and Immunology, 319, 131-156.
Smith, D. J., \& Taubman, M. A. (1987). Oral immunization of humans with Streptococcus sobrinus glucosyltransferase. Infection and Immunity, 55, 25622569.

Smith, D. J., \& Taubman, M. A. (1996). Experimental immunization of rats with a Streptococcus mutans 59-kilodalton glucan-binding protein protects against dental caries. Infection and Immunity, 64, 3069-3073.

Tao, R., Jurevic, R. J., Coulton, K. K., Tsutsui, M. T., Roberts, M. C., Kimball, J. R., et al. (2005). Salivary antimicrobial peptide expression and dental caries experience in children. Antimicrobial Agents and Chemotherapy, 49, 3883-3888.

da Silva Bastos, V. A., Freitas-Fernandes, L. B., Fidalgo, T. K., Martins, C., Mattos, C. T., de Souza, I. P., et al. (2015). Mother-to-child transmission of Streptococcus mutans: a systematic review and meta-analysis. Journal of Dentistry, 43, $181-191$. 